\title{
Chromosome 15q11-q13 Duplication Syndrome
}

National Cancer Institute

\section{Source}

National Cancer Institute. Chromosome 15q11-q13 Duplication Syndrome. NCI

Thesaurus. Code $\mathrm{C126692.}$

A syndrome caused by duplication of chromosome 15q11-q13. It is characterized by autism, mental retardation, ataxia, seizures, developmental delays, and behavioral problems. 